\title{
AVALIAÇÃO DO IMPACTO DOS BENEFÍCIOS DE ASSISTÊNCIA ESTUDANTIL SOBRE O DESEMPENHO ACADÊMICO: O CASO DA UNIVERSIDADE FEDERAL DO RIO GRANDE ${ }^{1,2}$
}

\author{
Gabriel Costeira Machado ${ }^{3}$ \\ Cristiano Aguiar de Oliveira ${ }^{4}$ \\ Tiaraju Alves de Freitas 5
}

0 Plano Nacional de Assistência Estudantil (PNAES) no Brasil tem fornecido um conjunto de benefícios que buscam garantir melhores condições para a permanência dos estudantes universitários identificados como socioeconomicamente vulneráveis. Vários estudos têm sido realizados para o Brasil em relação aos efeitos das políticas públicas em termos de evasão e de retenção dos discentes nas universidades. A partir de uma base de dados que concilia dois conjuntos de informações independentes, este artigo fez um pareamento de grupos que receberam benefícios do PNAES com os que não receberam, utilizando características observáveis comuns. 0 elemento central é a identificação das características socioeconômicas dos estudantes em conjunto com dados referentes ao desempenho em uma universidade pública, coletados no ano de 2015. Para estimaçãa dos resultados, utilizou-se o propensity score matching para diferentes tipos de benefícios concedidos (bolsa permanência, alimentação, moradia e transporte). Os resultados revelaram impacto positivo sobre o desempenho dos alunos.

Palavras-chave: avaliação de impacto; propensity score matching; PNAES; ensino superior.

\section{EVALUATION OF THE IMPACT OF STUDENT ASSISTANCE BENEFITS ON ACADEMIC PERFORMANCE: THE CASE OF THE FEDERAL UNIVERSITY OF RIO GRANDE}

The Plano Nacional de Assistência Estudantil (PNAES) [National Plan for Student Assistance] in Brazil has provided a set of benefits that seek to guarantee better conditions for the permanence of university students identified as socioeconomically vulnerable. Several studies have been carried out for Brazil regarding the effects of public policies in terms of student dropout and retention in universities. From a database that reconciles two sets of independent information, this article made a pairing of groups that received benefits from the PNAES with those that did not receive, using common observable characteristics. The central element is the identification of the socioeconomic characteristics of the students together with data referring to the performance in a public university, collected in the year 2015. Propensity Score Matching was used for different types of benefits granted (permanence scholarship, food, housing and transportation). The results showed a positive impact of receiving benefits on student performance.

Keywords: impact evaluation; propensity score matching; PNAES; higher education.

1. DOI: http://dx.doi.org/10.38116/ppp55art2

2. Este artigo foi apresentado durante o 3 Simpósio Avaliação da Educação Superior (Avalies 2017).

3. Doutorando em economia aplicada pela Universidade de São Paulo (USP).E-mail: <gmcosteira@usp.br>.

4. Professor no Programa de Pós-Graduação em Economia Aplicada da Universidade Federal do Rio Grande (PPGEA/ Furg).E-mail: <cristiano.oliveira@furg.br>.

5. Professor no PPGEA/Furg. E-mail: <tiarajufreitas@furg.br>. 


\section{EVALUACIÓN DEL IMPACTO DE LOS BENEFICIOS DE ASISTENCIA ESTUDIANTIL SOBRE EL DESEMPEÑO ACADÉMICO: EL CASO DE LA UNIVERSIDAD FEDERAL DE RIO GRANDE}

El Plan Nacional de Asistencia Estudiantil (PNAES) en Brasil ha proporcionado un conjunto de beneficios que buscan garantizar mejores condiciones para la permanencia de los estudiantes universitarios identificados como socioeconómicamente vulnerables. Se han llevado a cabo varios estudios para Brasil sobre los efectos de las políticas públicas en términos de deserción y retención de estudiantes en las universidades. A partir de una base de datos que concilia dos conjuntos de información independiente, este artículo realizó una combinación de grupos que recibieron beneficios del PNAES con los que no lo recibieron, utilizando características comunes observables. El elemento central es la identificación de las características socioeconómicas de los estudiantes junto con los datos referentes al desempeño en una universidad pública, recolectados en el año 2015. Lo pareamiento por puntaje de propensión [propensity score matching] se utilizó para diferentes tipos de beneficios otorgados (beca de permanencia, alimentación, vivienda y transporte). Los resultados mostraron un impacto positivo de recibir beneficios en el rendimiento del estudiante.

Palabras clave: evaluación de impacto; propensity score macthing; PNAES; educación superior.

\section{ÉVALUATION DE L'IMPACT DES PRESTATIONS D'AIDE AUX ÉTUDIANTS SUR LE RENDEMENT SCOLAIRE: LE CAS DE L'UNIVERSITÉ FÉDÉRALE DE RIO GRANDE}

Le Plan national d'assistance aux étudiants (PNAES) au Brésil a fourni une série d'avantages visant à garantir de meilleures conditions pour la permanence des étudiants universitaires identifiés comme vulnérables sur le plan socioéconomique. Plusieurs études ont été réalisées pour le Brésil sur les effets des politiques publiques en matière d'abandon scolaire et de rétention dans les universités. À partir d'une base de données qui réconcilie deux ensembles d'informations indépendantes, cet article a établi un appariement de groupes ayant bénéficié des avantages du PNAES avec ceux qui n'avaient pas reçu, en utilisant des caractéristiques observables communes. L'élément central est l'identification des caractéristiques socioéconomiques des étudiants et des données relatives à la performance dans une université publique, collectées en 2015. Le score de propension a été utilisé pour différents types de prestations accordées (bourse de permanence, nourriture, logement et transport). Les résultats ont montré l'impact positif de recevoir des avantages sur la performance des élèves.

Mots-clés: évaluation d'impact; propensity score matching; PNAES; enseignement supérieur.

JEL: $121 ; 123$. 


\section{INTRODUÇÃO}

Conforme contextualiza Trindade (2000), a instituição universitária, em seu modelo tradicional, surge de experiências pioneiras da França e da Bolonha, ainda no século XII, passando por inúmeras transformaçôes ao longo do tempo, em resposta às mudanças institucionais, sociais e culturais: do Renascimento, no século XV, com o aporte do humanismo literário e artístico, além das transformaçóes comerciais em decorrência do capitalismo, ao Iluminismo, no século XVIII, onde a ciência toma espaço no ambiente universitário. Nesse interím, a institucionalização do ensino superior se alastra por toda a Europa, aportando no Novo Mundo - as primeiras experiências foram a universidade de Santo Domingo, fundada no Caribe pelos colonizadores espanhóis em 1538, e a adoção do modelo dos colégios ingleses (Oxford e Cambridge) nas colônias norte-americanas a partir de 1636. O conceito de universidade estatal moderna - marcado pela tríade universidade, conhecimento e Estado - surge somente no século XIX, período em que o Brasil adotou o ensino superior profissional. Na década de 1930, fundou-se a Universidade de São Paulo, a partir da união da Faculdade de Filosofia, Ciências e Letras, da Escola Politécnica de São Paulo, da Escola Superior de Agricultura Luiz de Queiroz, da Faculdade de Medicina, da Faculdade de Direito e da Faculdade de Farmácia e Odontologia.

Nas palavras de Gilioli (2016), antes disso, o ensino superior brasileiro era constituído de uma reunião de escolas superiores isoladas. Um marco no sistema universitário brasileiro, contudo, foi a reforma universitária de 1968, decretada pela Lei no 5.540 , que previa o aumento das matrículas em instituiçóes de ensino superior (IES), principalmente em IES privadas. Um dos princípios norteadores da reforma foi o controle político das universidades públicas brasileiras e a formação de trabalhadores. As consequências de tal medida foram a ampliação do acesso ao curso superior, a ampliação de recursos e o desenvolvimento de programas de pós-graduação.

Entre 1965 e 1980, as matrículas do setor privado saltaram de 142 mil para 885 mil alunos, passando de $44 \%$ do total das matrículas para $64 \%$ nesse período. Em sua fase inicial, ou seja, desde o final dos anos de 1960 até a década de 1970, a expansáo do setor privado laico ocorreu basicamente através da proliferação de estabelecimentos isolados de pequeno porte. A partir da segunda metade da década de 1970, o processo de organizaçáo institucional do setor privado sofreu uma transformaçáo gradual (Martins, 2009, p. 23).

Ainda segundo Martins (2009), durante a década de 1980, a expansão do ensino superior foi freada em virtude da crise econômica, do contexto hiperinflacionário e das altas taxas de desemprego da época. Concomitante, o ensino superior privado foi alvo de críticas quanto à sua qualidade - o que suscitou uma suspensão temporária de criação de novos cursos nos estabelecimentos já existentes, por medidas legais. Na década de 1990, a demanda por educação superior teve 
um aumento expressivo. Ainda que as instituições privadas tenham absorvido um contingente maior, o ensino público era o mais procurado.

$\mathrm{Na}$ década seguinte, um conjunto de mudanças foi proposto, inclusive uma reforma universitária, em 2004, com vistas à democratização e à permanência dos alunos no ensino superior. As propostas obtiveram grande aporte, sobretudo a partir da criação do Programa de Apoio a Planos de Reestruturação e Expansão das Universidades Federais (Reuni), instituído pelo Decreto nº 6.096/2007, ${ }^{6}$ que tinha como principais objetivos a ampliação do acesso e a permanência de estudantes nas universidades.

Em 2007, a portaria normativa do Ministério da Educação (MEC) criou o Plano Nacional de Assistência Estudantil (PNAES), instrumento que, aliado ao Reuni, busca criar meios para a permanência dos jovens em situação de vulnerabilidade socioeconômica na educação superior pública federal - a citar, prioritariamente estudantes oriundos da rede pública de educação básica ou com renda familiar per capita de até um salário mínimo (SM) e meio, sem prejuízo de demais requisitos fixados pelas instituiçóes federais de ensino superior (Ifes), as quais cumpririam o papel de identificar, acompanhar o discente e detectar as dificuldades encontradas das mais diversas ordens, propondo medidas que garantissem sua permanência, através da concessão de benefícios financeiros ou de outra natureza. O programa foi implementado no ano seguinte e, em 2010, regulamentado pelo Decreto no 7.234 . $^{7}$

Assim, conforme os objetivos delimitados em seu escopo, o PNAES atuaria como uma ferramenta que trabalharia no combate à evasão e na retenção de alunos no ensino superior, com vistas à democratização do ensino. As questôes relacionadas à evasão de estudantes universitários são recorrentes em estudos das diversas áreas do conhecimento, os quais se debruçam sobre o tema em busca de respostas que ajudem a mitigar os fatores que desencadeiam tal fenômeno. Para Tinto (1993), por exemplo, a situação da evasão decorre de um processo multidimensional entre os discentes e a instituição de que fazem parte, tratando-se, portanto, de uma discussão que se exime de reducionismos. A literatura especializada tem mostrado que se trata, no entanto, de uma questáo de natureza complexa, sem que haja um consenso definitivo quanto aos determinantes que possam ser comuns a todos os casos. Questôes de natureza socioeconômica, como dificuldades financeiras,

6. 0 Reuni foi encerrado em 2012.

7. 0 Decreto o 7.234/2010 institui o Programa Nacional de Assistência Estudantil com o objetivo de: i) democratizar as condições de permanência dos jovens na educação superior pública; ii) minimizar os efeitos das desigualdades sociais e regionais na permenânecia e conclusão da educação superior; iii) reduzir as taxas de retensão e evasão; e iv) contribuir para a promoção da inclusão social pela educação. Para tanto, o programa atua em Ifes - abrangendo os institutos federais de educaçã̃o, ciência e tecnologia (IFETs) - através de ações que visem garantir os benefícios de moradia estudantil, alimentação, transporte, atenção à saúde, inclusão ditial, cultura, esporte, creche, apoio pedagógico e acesso, participação e aprendizagem de estudantes com deficiência, transtornos globais do desenvolvimento e altas habilidades e superdotação. 
contexto familiar e distância geográfica da família, aspectos pedagógicos e até perspectivas quanto ao curso e à profissão etc. Existe, porém, o entendimento de que as instituiçôes são os atores mais capazes de promover efetivas políticas de apoio aos estudantes para mitigar o fenômeno (Gilioli, 2016).

De acordo com o Censo da Educação Superior 2014, conduzido pelo Instituto Nacional de Estudos e Pesquisas Educacionais Anísio Teixeira (Inep, 2016), o percentual de alunos que abandonaram o curso para o qual foram admitidos chegou a 49\%. As razóes apontadas para a obtenção deste alto índice são muitas. Ainda que se refiram em maior número as IES privadas, trata-se de uma situação que merece atenção nas IES públicas também.

Embora se trate de uma problemática que afeta os sistemas educacionais de muitos países ao redor do mundo, a evasão é um fenômeno que tem ganhado visibilidade no Brasil nos anos recentes, sobretudo em virtude do grande fluxo de ingressantes em universidades públicas a partir das mudanças observadas na educação superior.

Entretanto, há mais de 30 anos, com vistas a melhorar o desempenho dos discentes, a Associação Nacional dos Dirigentes das Instituiçóes Federais de Ensino Superior (Andifes) atua, através do Fórum Nacional de Pró-Reitores de Assuntos Estudantis (Fonaprace), mediante açoóes, como, por exemplo, com a criação de indicadores auditáveis e mensuráveis para avaliar o desempenho dos discentes.

No período mais recente, o esforço da Andifes, somado aos relatórios técnicos independentes que auditam como os benefícios são geridos, ${ }^{8}$ incluindo as pesquisas acadêmicas realizadas ao longo do tempo, promove um ambiente que pode potencializar o efeito destes benefícios ao longo do tempo em termos de melhora dos índices de evasão, de retenção e, por conseguinte, de conclusão do ensino superior.

Estudos mais recentes também têm buscado medir e analisar a questáo da evasão frente às mudanças no ingresso no ensino superior, ou seja, o efeito do Sistema de Seleção Unificado (Sisu) na evasão. Isto é importante, visto que antes da implantação do Sisu nas IES o ingresso no ensino público superior era descentralizado, com os alunos se candidatando diretamente e de forma independente em cada instituição (Li, 2016). Após a implantação do Sisu, o sistema passou a ser centralizado para a maior parte dos candidatos. Existe uma autoridade central na qual os alunos encontram a um rol de alternativas de cursos e a seleção ocorre após a realização de uma única prova, que pode ser utilizada em várias universidades em todo o país, permitindo ao candidato optar por vaga que venha a surgir entre as IES. 
Para o candidato ao ensino superior, é lógico dizer que houve uma diminuição dos custos para que ele concorra a vagas em várias IES. Em princípio, o Sisu propicia um aumento da mobilidade estudantil, seja entre municípios de um mesmo estado, seja entre estados da Federação. Li (2016) cita que o MEC mediu que o Sisu apresentou uma taxa de mobilidade em sua primeira edição de $25 \%$ e que antes do Sisu o percentual era de 1\%. Ademais, Li (2016) e Machado e Szerman (2015) estimaram a influência do Sisu no ambiente de acesso ao ensino superior na evasão dos alunos e chegaram ao resultado de $4,5 \%$ e de $4,4 \%$, respectivamente, em termos de probabilidade de aumento da evasão.

Diante dessa perspectiva, portanto, este artigo utilizar-se-á de informaçôes de uma IES específica, a Universidade Federal do Rio Grande (Furg), para medir o impacto do recebimento de benefícios concedidos a estudantes identificados como grupo vulnerável sobre seu desempenho acadêmico, utilizando a informação do coeficiente de rendimento como uma proxy para essa mensuração. É levantada a hipótese de que, ao proporcionar a assistência estudantil a um grupo identificado de discentes, com vistas a cumprir a finalidade de mitigar os níveis de evasão ou, de outra forma, contribuindo para a sua permanência ao longo do curso de graduação, poderá haver reflexos sobre o desempenho desse grupo beneficiado. Assim, com o objetivo de testar tal hipótese, este estudo busca avaliar o efeito das medidas do PNAES sobre o desempenho acadêmico dos discentes da Furg. Para este fim, foi escolhida como sendo a estratégia empírica mais adequada para responder a este problema de pesquisa o propensity score matching (PSM).

A maioria dos trabalhos que compuseram a revisáo de literatura deste estudo identifica pesquisas sobre a evasão e a retenção no Brasil, porém, destaca-se o trabalho de Saccaro, França e Jacinto (2016), o qual propôs avaliar o efeito da política do PNAES em IES no Brasil. Os autores buscaram responder se os alunos que receberam a bolsa permanência do PNAES evadiram menos do que um grupo que não recebeu o benefício entre os anos de 2009 e 2012. De uma forma geral, seus resultados mostraram que as chances de recebimento do benefício modificam-se "de acordo com as características dos indivíduos e das universidades e que a evasão é menor entre os estudantes que receberam o auxílio" (Saccaro, França e Jacinto, 2016, p. 1).

Além desta introdução, a seção 2 apresenta uma breve revisão da literatura sobre o tema; a seção 3 traz a estratégia empírica adotada para avaliar o impacto dos benefícios PNAES na Furg, em que se analisa a metodologia do PSM, bem como a base de dados que integra este estudo, com análise descritiva; a seção 4 apresenta os resultados; e, por fim, a seção 5 faz as considerações finais. 


\section{REVISÃO DA LITERATURA}

A literatura acadêmica apresenta um amplo espectro de áreas realizando investigações teóricas e empíricas sobre o tema central educação no ensino superior. Temas relacionados com o nível de perseverança dos discentes para concluírem suas formaçôes, com o nível de evasão aos cursos, com o nível de retenção, com os efeitos dos financiamentos públicos ou privados concedidos aos acadêmicos, todas estas perspectivas, têm sido objeto de investigaçóes por pesquisadores da área da economia, da psicologia, da educaçáo, da sociologia, entre outras.

Libâneo (2007) aponta a açáo educativa - a qual compreende todos os processos de aprendizado ao longo da vida de um indivíduo, intencional ou não intencional - como um fenômeno global que é intrínseco e indissociável da sociedade. Para o autor, a educação tem o poder de moldar a sociedade, da mesma forma que os agentes responsáveis pelo planejamento do sistema educacional podem, por meio da educação, determinar o tipo de sociedade que buscam definir.

Através dessa conexão entre educação e sociedade, indivíduos e grupos travam relaçóes recíprocas diante da necessidade de trabalharem conjuntamente para garantir sua sobrevivência (Libâneo, 2007); e, justamente destas relaçôes, de acordo com as características individuais de cada um dos elos, estabelece-se a divisão do trabalho, a qual, ao longo da história, tem sido remodelada e vem assumindo formas que, em síntese, culminaram nas desigualdades socioeconômicas que se intensificaram, de acordo Libâneo (2007), na dinâmica capitalista de produção.

A desigualdade socioeconômica determina não somente a desigualdade de acesso a recursos materiais, mas, também, o acesso à cultura e à educaçáo, o que, sob uma perspectiva ampla, perpetua a pobreza, ao impedir a mobilidade social que a educação, enquanto fenômeno transformador, pode propiciar. A evasão pode ser igualmente interpretada como uma supressão do processo transformador da educação e, tratando-se de indivíduos de estratos sociais mais baixos, da incapacidade de romper o ciclo de pobreza. Na sociologia, conforme destacam Lima Júnior, Ostermann e Rezende (2012), tal fenômeno é tido como um problema complexo, por envolver diferentes agentes que compóem o processo educacional, direta ou indiretamente. Desse modo, ainda que de forma não consensual, no que se refere à liberdade individual, entende-se que o estudante é relativamente livre em suas escolhas.

Sob essa ótica, Nogueira e Nogueira (2002) apresentam uma revisão da contribuição de Pierre Bourdieu no campo da sociologia da educação. Bourdieu, na década de 1960, faz uma reinterpretaçáo do papel do sistema de ensino na sociedade, ao romper com a visão otimista de que a educação pública gratuita, por si, seria capaz de conceder condiçôes igualitárias de competir e, por meio da meritocracia, os indivíduos poderiam avançar em suas carreiras e sobrepujar 
seus status sociais. A teoria de Bourdieu decorre da constatação de que o sistema educacional funcionalista detinha caráter autoritário e elitista, com baixo retorno social e econômico auferido pelos certificados escolares no mercado de trabalho (Nogueira e Nogueira, 2002). Bourdieu também estabelece uma relação entre desempenho escolar e origem social, de modo que, esta última determinava sua trajetória escolar e as chances de obter sucesso, logo, sendo capaz de intensificar as desigualdades sociais, de forma que, a educação, na visão de Bourdieu, é tomada como uma instituição que mantinha privilégios. A partir desta constatação, Bourdieu elaborou um sistema teórico que descreve um processo de perpetuação das condiçôes de participação social por meio da herança social, ou, ainda, a sua bagagem socialmente herdada. ${ }^{9}$

Costa e Lopes (2008) propuseram uma análise das diferentes características do ensino superior português e dos seus discentes. A análise se dá em três diferentes níveis, denominados estrutural, individual e institucional. Estudos baseados no primeiro dos níveis constituem-se de pesquisas envolvendo dados agregados, uma amostra consistente com o potencial de responder de que forma o desempenho e a trajetória escolar são influenciados pelos aspectos socioeconômicos dos estudantes. Por outro lado, a análise individual propóe uma pesquisa microfundamentada, buscando analisar como o indivíduo apresenta características que o aproxima ou o distancia do indivíduo médio - aquele determinado pela análise estrutural. Por fim, a análise institucional preocupa-se em estudar as relaçóes que se estabelecem na instituição de ensino e, além disso, verificar de que forma essas relações podem influenciar o desempenho do aluno.

De uma forma quantitativa, Costa e Lopes (2008) identificam que houve um aumento significativo tanto no número de ingressantes quanto no número de formados na primeira metade do século XXI. Porém, permanece em dois terços a relação entre os ingressantes e os formados. Os autores mostram, ainda, através de estudos de caso, como é moldado o sucesso ou o insucesso de um curso, o qual envolve suas competências e a conexão com o mercado de trabalho, por exemplo, a utilização de práticas inovadoras como apoio à formação do estudante. Outro elemento presente em Costa e Lopes (2008) é uma fotografia realizada por meio de entrevistas mais robustas com 170 discentes. As variáveis que surgiram como relacionadas ao sucesso na passagem dos discentes pelo ensino superior foram: a articulação com o ensino secundário; o corpo docente, em termos de preparação e formação pedagógica; e os cursos serem práticos ou teóricos.

9. É importante lembrar que não é o objetivo principal deste artigo analisar com profundidade como a sociologia da educação, através de autores clássicos como Bourdieu, trabalha o tema, busca-se mostrar neste trabalho como a sociologia da educação e a economia trabalham este tema comum. 
O sociólogo Tinto $(1975 ; 1993)$ propóe um modelo teórico para identificar as principais condicionantes do desempenho dos acadêmicos do curso superior e suas implicações em termos do nível de evasão nas universidades. Fatores apontados por Tinto $(1975 ; 1993)$ assinalam que a evasão decorre das influências sociais e intelectuais exercidas sobre os estudantes. Contexto familiar, renda familiar, atributos individuais gerais, escolaridade anterior, atributos motivacionais e de expectativas, habilidades do ingressante ao ensino superior, seu desempenho durante a faculdade e sua persistência estão entre as principais variáveis citadas por Tinto (1975).

Destaca-se que Tinto $(1975 ; 1993)$ indica a renda como uma variável cada vez menos importante em relação à evasão ao ensino superior. $\mathrm{O}$ autor atualizou seu modelo-base de 1975 com a inclusão de um conjunto de variáveis: aprendizagem, finanças, ajustamento, incongruência, isolamento, dificuldade e compromissos externos. De forma geral, Tinto apontou que as características individuais, as experiências ou os compromissos pregressos em conjunto com as características da instituição de ensino superior - demais discentes, docentes e corpo administrativo - envolvem o conjunto de informaçáo que afetará o nível de persistência dos discentes durante sua formação de ensino superior (figura 1). Este conjunto de variáveis pode impactar na decisão do discente não só em evadir ao ensino superior, mas também em ficar retido acima do tempo máximo para a conclusão do curso. É importante que o discente busque um equilíbrio entre as variáveis, denominadas por Tinto (1993) de "integraçáo acadêmica" e de "integraçáo social". ${ }^{10}$

10. Citou-se aqui o modelo de Tinto (1975; 1993), mas existem outros modelos desenvolvidos pela literatura internacional que se diferenciam ao de Tinto, mas que em essência guardam os axiomas básicos do que influencia o desempenho dos discentes no ensino superior. Para uma primeira pesquisa sobre os outros modelos, recomenda-se a leitura de Santos (2013) e Cislaghi (2008). Para mais detalhamento do que envolvem cada uma das variáveis presentes no modelo de Tinto, indica-se que seus trabalhos aqui citados sejam consultados. 


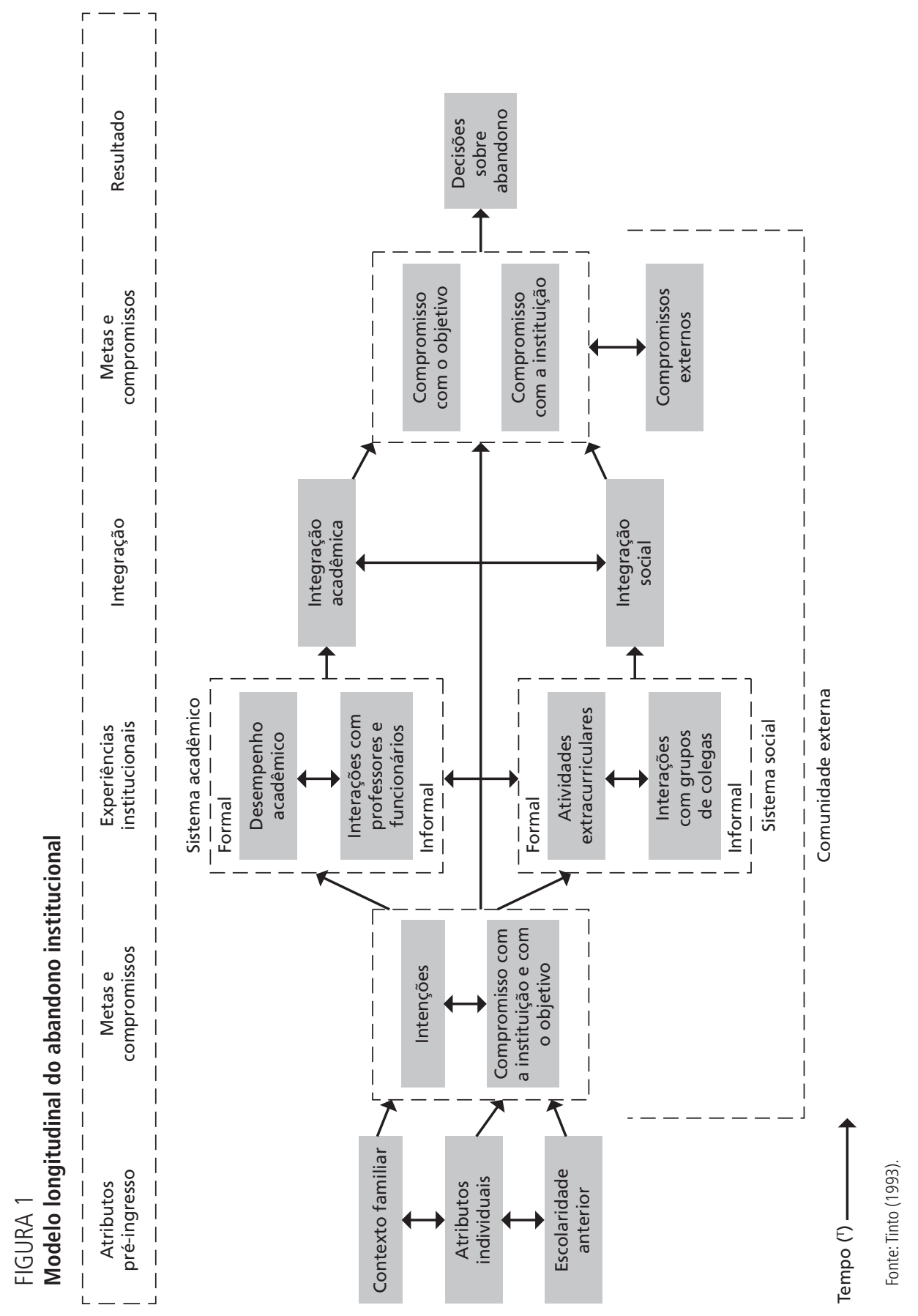


Borges (2011) e Martins (2007) destacam que trabalhos presentes na literatura nacional convergem para as contribuições de Tinto (1993). Itens específicos e pontuais que fazem parte dos conjuntos relevantes em relação ao desempenho dos discentes no ensino superior. Baixo nível de renda dos discentes, gestores ineptos em realizarem açôes que promovam a permanência do estudante frente a dificuldades durante o curso, uma não diferenciação do curso em termos de qualidade em relação aos demais, a influência familiar, não ser vocacionalmente voltado para a área, a localização da instituição, o fato do aluno trabalhar concomitante ao ensino superior, a idade do discente e as reprovaçóes em disciplinas da área de matemática. Isto tudo vem ratificar o problema que se está posto em relação às variáveis que afetam a desistência por parte dos discentes do ensino superior.

Bratti (2007), em estudo econométrico realizado com jovens de 16 anos na Inglaterra e no País de Gales com dados de 1970, identificou que, mesmo que tenha um efeito inverso entre renda familiar e evasão escolar, conclui-se que o peso da renda familiar é relativamente pequeno para influenciar a evasão, confirmando Tinto (1975). As principais variáveis identificadas por Bratti (2007), que implicam maior probabilidade de os alunos deixarem a escola, são a escolaridade dos pais e a constante presença do interesse dos pais na educação dos filhos.

Em face disso, Cislaghi (2008) diz que, apesar dos modelos conceituais puros ou expandidos como os de Tinto (1993) e outros semelhantes ${ }^{11}$ se empenharem em ampliar o alcance da explicação da ocorrência de evasão, o máximo verificado em estudos empíricos atinge até $70 \%$ da explicação da variância.

Uma referência nacional encontrada na literatura sobre desempenho dos discentes no ensino superior é o trabalho de Sousa et al. (2015), o qual cita diversos autores internacionais ${ }^{12}$ que abordam a questão da evasão como um processo multidimensional, pois envolve os órgãos responsáveis pelas políticas públicas e suas ações na busca de minimizar as taxas de evasão ao longo do tempo. A evasão seria afetada por fatores socioeconômicos (nível alto de pobreza), causas relativas ao professor (qualidade do ensino), causas relativas ao aluno (por exemplo, nível ideal de alimentação em termos nutricionais) e causas relativas às práticas pedagógicas e institucionais (avaliação inadequada dos processos e regulamentos rígidos).

Destaca-se aqui o trabalho de Rumberger e Lima (2008 apud Sousa et al., 2015), o qual identificou, através de uma revisão teórica de 203 estudos, que o

11. Modelo do processo de abandono, de Spady; modelo de desgaste de estudantes, de Bean; modelo conceitual do impacto dos ambientes universitários, de Pascarella; modelo do envolvimento do estudante, de Astin; modelo de desgaste de estudantes adultos, de MacKinnon e Slaney; modelo integrado de permanência, de Cabrera, Castañeda, Nora e Henstler; modelo de comprometimento estudante-instituição depois do primeiro ano, de Nora, Barlow e Crisp; modelo conceitual do abandono do estudante em IES de tempo parcial, de Braxton, Hirschy e McClendon.

12. Caetano (2005), Bratti (2007), Rumberger e Lima (2008) e Mahuteau e Mavromaras (2013). 
ambiente familiar estável e o acesso a recursos sociais e financeiros têm impacto significativo sobre a probabilidade dos estudantes concluírem seus estudos.

Outra referência nacional recente é a pesquisa de Saccaro, França e Jacinto (2016), que cita o artigo de Murdock (1989 $9^{13}$ apud Saccaro, França e Jacinto, 2016), que também envolveu uma revisão de literatura a respeito do tema auxílio financeiro e persistência do estudante nos Estados Unidos (Saccaro, França e Jacinto, 2016, p. 2). Os autores encontraram que "a taxa de evasão dos estudantes contemplados com a bolsa [permanência] se mostrou inferior em comparação com os demais, logo, aumentando as chances dos estudantes menos abastados concluírem o ensino superior" (Saccaro, França e Jacinto, 2016, p. 15).

A questão dos diversos tipos de auxílio financeiro foi objeto de investigação de Cappelli e Won (2016). Estes citam que a ajuda financeira vem sendo utilizada cada vez mais com maior frequência como uma política de acesso ao ensino universitário. Destacam que existem três tipos básicos de benefício financeiro aos estudantes de ensino superior. O subsídio, que não necessita ser reembolsado; os empréstimos, que são reembolsáveis no futuro; e, por fim, a bolsa trabalho, uma permuta de trabalho feita pelo estudante em troca da educação recebida. A pergunta dos autores é se há diferença entre os tipos disponíveis de ajuda financeira e os desempenhos alcançados pelos estudantes. Os resultados encontrados por Cappelli e Won (2016), aplicados para os Estados Unidos, mostram que os estudantes que receberam auxílio com base em suas necessidades têm uma performance melhor que aqueles que não receberam ajuda financeira e, por fim, aqueles que pagam o ensino superior com empréstimos têm um desempenho pior quando comparados com outras formas de auxílio.

Silva (2013), em sua revisão de literatura, aponta que os resultados para o caso brasileiro sobre evasão no ensino superior indicam que as principais razóes seriam a falta de perspectiva na carreira, o baixo comprometimento com o curso, a baixa participação nas atividades acadêmicas, a falta de apoio familiar e o baixo desempenho escolar.

Sousa et al. (2015) buscaram identificar as principais razốes sobre o nível de evasão e reprovação dos estudantes nos cursos tecnológicos do Instituto Federal de Ciência e Tecnologia do Ceará (IFCE). Utilizando dados em painel com informaçóes dos cursos para o período 2006-2013, os autores concluíram que seria importante criar ou ampliar políticas públicas que propiciassem o aumento da renda das famílias dos estudantes e o investimento em educação pública em seu sentido amplo.

13. Murdock, T. Does Financial Aid Really Have an Effect on Student Retention? Journal of Student Financial Aid, v. 19, n. 1, 1989. Disponível em: <https://bit.ly/3eS7pNZ>. 
O objetivo de Saccaro, França e Jacinto (2016) foi verificar o efeito da bolsa permanência concedida via PNAES em relação à taxa de evasão para os alunos cotistas nas Ifes. $\mathrm{O}$ método utilizado para medir o efeito do benefício foi através de diferenças em diferenças. $\mathrm{O}$ resultado encontrado pelos autores confirma o efeito positivo esperado do benefício sobre os estudantes socioeconomicamente vulneráveis em relação à diminuição do nível de evasão neste grupo.

Por fim, pode-se notar que, mesmo encontrando uma ampla linha de pesquisa sobre o tema entre diversas áreas do conhecimento de forma independente uma das outras, existe uma complexidade de razóes que podem afetar o desempenho dos acadêmicos. Condiçóes familiares, desempenho prévio nas escolas anteriores ao ingresso dos discentes, esforço do discente durante o nível superior e auxílio financeiro enquanto cursa a faculdade encontram validação para que o desempenho dos acadêmicos implique uma maior probabilidade de concluir o curso superior. A questão é qual seria a relação entre estas variáveis tendo como objeto uma instituição pública de ensino superior que possibilitasse uma base de dados específica. Específica no sentido de fornecer informaçóes socioeconômicas prévias ao ingresso dos discentes ao ensino superior em conjunto com o desempenho destes mesmos discentes, associado ao fato de receberem os benefícios do PNAES do governo federal brasileiro.

\section{ESTRATÉGIA EMPÍRICA}

A missão de uma avaliação de impacto, por assim dizer, é analisar se determinado programa está alcançando os objetivos esperados. Assim, tratando-se de políticas públicas, as metodologias que buscam avaliar seus impactos têm como principal desafio responder quais teriam sido os resultados dos beneficiários na ausência desta intervenção. $\mathrm{O}$ resultado consiste na diferença entre essas duas situaçóes: o grupo de beneficiários após tratamento e o mesmo grupo sem o recebimento do tratamento, convencionalmente chamados de grupo tratado e de grupo controle, respectivamente. Dessa forma seria possível responder se os resultados que os indivíduos expostos à intervenção obtiveram são frutos do tratamento, propriamente, ou se devem a outros fatores não correlatos a este.

A dificuldade, no entanto, reside no fato de que o pesquisador não observa o grupo de controle, ou seja, são situações mutuamente excludentes: não é possível observar os mesmos indivíduos em ambas as situaçốes simultaneamente. O desafio maior consiste em adequar um grupo de indivíduos de forma que sejam capazes de representar aquele grupo tratado na ausência de tratamento, fugindo de comparaçôes de resultados antes e depois por simples diferenças de médias, ou ainda, de beneficiários ou não beneficiários, simplesmente. Para tanto, o pesquisador se utiliza de metodologias capazes de mitigar os problemas estatísticos incumbentes. Neste rol, o método econométrico escolhido como sendo o mais apropriado para a proposta deste estudo é o PSM. 
A estratégia se tornou um método popular para estimação dos efeitos médios de tratamento na literatura de avaliação, sendo considerada uma boa escolha para as situações em que as características observáveis são responsáveis por influenciar a participação em um determinado programa. Amplamente usado para pesquisas de mercado de trabalho, como avaliaçóes de impacto de treinamentos de trabalhadores, mas cada vez mais aplicado a diferentes áreas. Por exemplo, França e Gonçalves (2010) usam o método PSM para medir as diferenças de desempenho entre escolas do ensino fundamental da rede pública e privada na fase inicial do ensino fundamental, utilizando os dados do Sistema Nacional de Avaliação da Educação Básica (Saeb), estabelecendo como estratégia de identificação o tratamento baseado na concessão de vouchers para alunos socioeconomicamente vulneráveis estudarem em escolas privadas e, dessa forma, identificando um efeito positivo sobre tal tratamento.

Ainda na área da educação, Duenhas, França e Gonçalves (2011) buscaram verificar a eficácia do Programa Comunidade Escola em reduzir a violência interna, de acordo com a percepção dos diretores das escolas que integravam o programa, as que aguardavam para ingressar e aquelas que não possuíam interesse em participar (formando, portanto, dois contrafactuais). Para tanto, os autores utilizaram-se do método de pareamento por escore de propensão para estimar através do método de mínimos quadrados ponderados o efeito de tratamento, o qual mostrou um efeito positivo do programa para as escolas, embora a tornasse mais vulnerável à violência externa.

\subsection{Método}

A ideia do método consiste em encontrar um grupo de controle que seja o mais parecido possível com o grupo de tratamento em termos de características observáveis que não são afetadas pelo programa. Assim, o PSM gera um grupo de comparação estatístico baseado em um modelo de probabilidade-padrão, como o Probit ou Logit, e, então, calcula a probabilidade de um indivíduo ser beneficiário, considerando um conjunto de características observáveis e, através disto, combina as informaçóes de modo a formar um grupo de comparação que se assemelhe àquele que foi exposto ao tratamento. $\mathrm{O}$ efeito médio de tratamento é calculado como sendo a diferença média entre os resultados obtidos entre esses dois grupos.

Formalmente, o escore de propensáo é definido por Rosenbaum e Rubin (1983) como sendo a probabilidade condicional de receber o tratamento dadas as características observáveis (pré-tratamento):

$$
\mathrm{p}(\mathrm{X}) \equiv \operatorname{Pr}(\mathrm{D}=1 \mid \mathrm{X})=\mathrm{E}(\mathrm{D} \mid \mathrm{X})
$$


em que: $\mathrm{D}=\{0,1\}$ é o indicador de exposição ao tratamento, assumindo o valor zero se o indivíduo náo recebe tratamento e um caso receba; e X é o vetor de características observadas, onde estão contidas as variáveis que definem o indivíduo.

Segundo Rosenbaum e Rubin (1983), sejam as unidades definidas pelo índice $\mathrm{i}$, se o escore de propensão $\mathrm{p}\left(\mathrm{X}_{\mathrm{i}}\right)$ for calculado, entáo o efeito médio de tratamento sobre os tratados (ATT), definido por $\tau$, pode ser estimado como segue:

$$
\begin{gathered}
\tau \equiv E\left\{Y_{1 \mathrm{i}}-\mathrm{Y}_{0 \mathrm{i}} \mid \mathrm{D}_{\mathrm{i}}=1\right\} \\
\left.=\mathrm{E}\left[\mathrm{E}\left\{\mathrm{Y}_{1 \mathrm{i}}-\mathrm{Y}_{0 \mathrm{i}} \mid \mathrm{D}_{\mathrm{i}}=1\right\}, \mathrm{p}\left(\mathrm{X}_{\mathrm{i}}\right)\right\}\right] \\
=\mathrm{E}\left[\mathrm{E}\left\{\mathrm{Y}_{1 \mathrm{i}} \mid \mathrm{D}_{\mathrm{i}}=1, \mathrm{p}\left(\mathrm{X}_{\mathrm{i}}\right)\right\}-\mathrm{E}\left\{\mathrm{Y}_{0 \mathrm{i}} \mid \mathrm{D}_{\mathrm{i}}=0, \mathrm{p}\left(\mathrm{X}_{\mathrm{i}}\right)\right\} \mid \mathrm{D}_{\mathrm{i}}=1\right],
\end{gathered}
$$

em que: $\mathrm{Y}_{1 \mathrm{i}}$ e $\mathrm{Y}_{0 \mathrm{i}}$ são os resultados dos grupos tratado e controle, respectivamente.

A fim de obter uma estimação de $\tau$ consistente, um conjunto de hipóteses deve ser assegurado. Formalmente, tem-se a hipótese de balanceamento das variáveis observáveis conforme o escore de propensão, $\mathrm{p}(\mathrm{X})$.

$\mathrm{D} \perp \mathrm{X} \mid \mathrm{p}(\mathrm{X})$.

Satisfazendo essa condição, para um dado escore de propensão, a exposição ao tratamento é aleatória e, portanto, tratados e controles devem ser, na média, idênticos.

A seguir, a hipótese de independência condicional, a qual mostra que, dado um conjunto de variáveis observáveis $\mathrm{X}$ que não são afetadas pelo tratamento, os resultados potenciais $Y$ são independentes da atribuição ao tratamento, o que implica que a atribuição ao tratamento é dada com base, somente, nas características observáveis. Formalmente,

$$
\mathrm{Y}_{1}, \mathrm{Y}_{0} \perp \mathrm{D} \mid \mathrm{X} .
$$

Por último, tem-se a hipótese de suporte comum que garante que as observaçóes tratadas possuem observaçóes controle correspondentes que estejam próximas na distribuição do escore de propensão e permitam medir o efeito médio de tratamento sobre o tratado, $\tau$.

$$
0<\operatorname{Pr}\left(D_{\mathrm{i}}=1 \mid \mathrm{X}_{\mathrm{i}}\right)<1 .
$$

Consequentemente, a efetividade do PSM também depende da existência de um grande número de observaçóes tratadas e um correspondente número de observaçôes de controle no mínimo semelhantes, para que, assim, uma região de suporte comum possa ser estabelecida. 


\subsection{Base de dados e análise descritiva}

Conforme aponta a revisão da literatura, uma pesquisa que busque verificar o efeito de uma política social, como os benefícios concedidos pelo PNAES, necessita de uma base de dados que contemple no mínimo dois conjuntos de variáveis, a saber, variáveis que caracterizem o estudante antes de entrar em uma universidade e, também, variáveis que demonstrem seu desempenho após seu ingresso no ensino superior. A base de dados utilizada neste artigo contempla ambas as situaçóes. A primeira através das respostas dos estudantes que ingressaram em uma instituição federal de ensino superior por meio do questionário socioeconômico do Exame Nacional do Ensino Médio (Enem) de 2011 e 2012. ${ }^{14}$ A segunda através do desempenho acadêmico dos discentes matriculados no final do ano letivo referente ao ano de 2015. ${ }^{15}$ Este tipo de conciliação de bases de dados com características observáveis anteriores e posteriores ao ingresso dos estudantes no ensino superior não é encontrado na literatura acadêmica nacional recente, principalmente após a implantação do PNAES. Esta estratégia se concilia com o modelo de Tinto (1993) ao propiciar a inclusáo de elementos de atributos pré-ingresso.

Em um levantamento realizado pela CGU, ${ }^{16}$ junto a 32 universidades federais, foi constatado que não existe uma uniformidade na forma de condução, por parte das Ifes, do acompanhamento dos resultados alcançados pelos estudantes que receberam os benefícios do PNAES (CGU, 2017). O relatório da CGU identificou que $50 \%$ das Ifes regulamentaram o PNAES. Inclusive a Furg, a qual é objeto deste estudo, é citada no relatório pela CGU (2017) como exemplo, primeiro, de boas práticas em relação à infraestrutura disponibilizada para o gerenciamento dos recursos do PNAES e, segundo, por ter criado uma regulamentação própria para o PNAES. ${ }^{17}$

A Furg tem em sua estrutura organizacional a Pró-Reitoria de Assuntos Estudantis (Prae), que tem como objetivo propiciar condiçóes equitativas de acesso e permanência dos estudantes. A universidade concede benefícios vinculados ao Subprograma de Assistência Básica (SAB) (alimentação, moradia, transporte, pré-escola e auxílio-permanência). A manutenção dos auxílios ao longo de sua

\footnotetext{
14. Os dados de 2011 e 2012 do questionário socioeconômico dos estudantes que realizaram o Enem e que ingressaram na Furg foram disponibilizados pelo Sistema Sisu logo depois de finalizado o processo de ingresso na universidade em cada ano. A partir do ano de 2013, esta informação deixou de ser fornecida. 0 que existe atualmente é uma base de dados dos estudantes que responderam o questionário do Enem, mas que não permite mineralizar por instituição de ensino superior. Isto impede que se possam gerar novas conciliações entre o questionário socioeconômico do Enem e 0 do desempenho acadêmico.

15. Os dados foram obtidos junto ao Núcleo de Tecnologia da Informação (NTI) da Furg.

16. A CGU é órgão do governo federal responsável, entre outras atribuições, pela defesa do patrimônio público, pela transparência e pelo combate à corrupção.

17. Instrução Normativa no 3/2011, sobre alimentação estudantil do Subprograma de Assistência Básica; Instrução Normativa no 2/2012, sobre concessão de bolsas permanência; Instrução Normativa no 4/201,1 sobre transporte; Instrução Normativa no 5/2011, sobre pré-escola.
} 
formação na universidade depende dos discentes terem frequência igual ou superior a $75 \%$, coeficiente de rendimento maior ou igual a cinco e, que a quantidade de créditos por período seja igual ou superior a 15 créditos, ou 225 horas. Aos discentes que venham a apresentar dificuldades de aprovação nas disciplinas, a Furg oferece a oportunidade de manutenção do benefício desde que o acadêmico opte por participar de acompanhamento pedagógico no período posterior ao que apresentou dificuldades. Com esta atividade busca-se identificar situaçóes pontuais de dificuldades que venham a surgir e buscar com o acompanhamento auxiliar o estudante frente a estas situações com, por exemplo, apoio psicológico e pedagógico (Furg, 2011a; 2011b; 2011c; 2016).

Outro ponto muito importante que consta no relatório da CGU (2017) foi a necessidade das Ifes verificarem o resultado que os benefícios têm alcançado para o grupo de estudantes beneficiados. A avaliação de políticas públicas é de suma importância para verificar o grau de eficiência da política. Foi identificado pela CGU que apenas três das 32 Ifes realizavam algum tipo de avaliação dos resultados do PNAES, citando a Universidade Federal do Acre (Ufac), a Universidade Federal do Paraná (UFPR) e a Universidade Federal do Sergipe (UFS) como sendo estes casos.

$\mathrm{Na}$ base de dados aqui utilizada, o corte temporal dos dados de desempenho acadêmico dos estudantes refere-se ao período do segundo semestre de 2015, no nível de graduação na Furg para os cursos presenciais. Obtiveram-se, neste caso, 8.842 observaçôes, sendo cada observação igual a um estudante. Cada observação apresenta o desempenho dos discentes nesse período, envolvendo todos os cursos e todos os campi - Campus de Rio Grande, Campus de Santo Antônio da Patrulha, Campus de Santa Vitória do Palmar e Campus de São Lourenço do Sul, todos localizados no estado do Rio Grande do Sul. A seguir, foi feita a consolidação entre as duas bases de dados - questionário socioeconômico do Enem e base de dados do desempenho dos estudantes universitários -, gerando um conjunto de informação com 2.254 discentes. ${ }^{18} \mathrm{O}$ próximo passo foi suprimir da amostra aqueles alunos com coeficiente de rendimento nulo, pois, a priori, não se pode determinar o que explica tal desempenho e caracteriza-lo como retido ou ingressante, tornando-se necessário uma metodologia estatística apropriada para tal. Em suma, o estudo contou com uma amostra final de 1.910 estudantes.

A fim de conhecer a amostra final com a qual se está trabalhando, a tabela 1 apresenta o grupo de estudantes de acordo com sexo, cor ou raça e tipo de escola de origem - ensino fundamental ou médio. 
TABELA 1

Distribuição dos discentes de acordo com sexo, etnia e procedência escolar

\begin{tabular}{|c|c|c|c|c|c|c|c|c|c|c|c|c|c|}
\hline & \multicolumn{2}{|c|}{ Brancos } & \multicolumn{2}{|c|}{ Pretos } & \multicolumn{2}{|c|}{ Pardos } & \multicolumn{2}{|c|}{ Amarelos } & \multicolumn{2}{|c|}{ Indígenas } & \multicolumn{2}{|c|}{ Não informado } & \multirow{2}{*}{ Total } \\
\hline & Pública & Privada & Pública & Privada & Pública & Privada & Pública & Privada & Pública & Privada & Pública & Privada & \\
\hline Feminino & 608 & 215 & 62 & 8 & 100 & 22 & 3 & 3 & 1 & 0 & 17 & 4 & 1.043 \\
\hline Masculino & 451 & 233 & 39 & 8 & 92 & 12 & 2 & 4 & 0 & 0 & 21 & 5 & 867 \\
\hline \multirow{2}{*}{ Total } & 1.059 & 448 & 101 & 16 & 192 & 34 & 5 & 7 & 1 & 0 & 38 & 9 & \multirow{2}{*}{1.910} \\
\hline & \multicolumn{2}{|c|}{1.507} & \multicolumn{2}{|c|}{117} & \multicolumn{2}{|c|}{226} & \multicolumn{2}{|c|}{12} & \multicolumn{2}{|c|}{1} & \multicolumn{2}{|c|}{47} & \\
\hline
\end{tabular}

Fonte: Dados da pesquisa.

Elaboração dos autores.

Do total de 1.910 estudantes que compóem a amostra, a maioria absoluta (aproximadamente 79\%) é branca, seguidos por pardos (aproximadamente 12\%) e pretos $(6 \%)$, enquanto amarelos e indígenas representam menos de $1 \%$ da amostra. A maioria dos indivíduos é do sexo feminino (aproximadamente 55\% da amostra). Por fim, o somatório dos estudantes oriundos de escolas públicas contempla 1.396 alunos (73\% da amostra).

O gráfico 1 apresenta a distribuição dos estudantes de acordo com a idade em um histograma. A amostra é composta majoritariamente por jovens com menos de 25 anos.

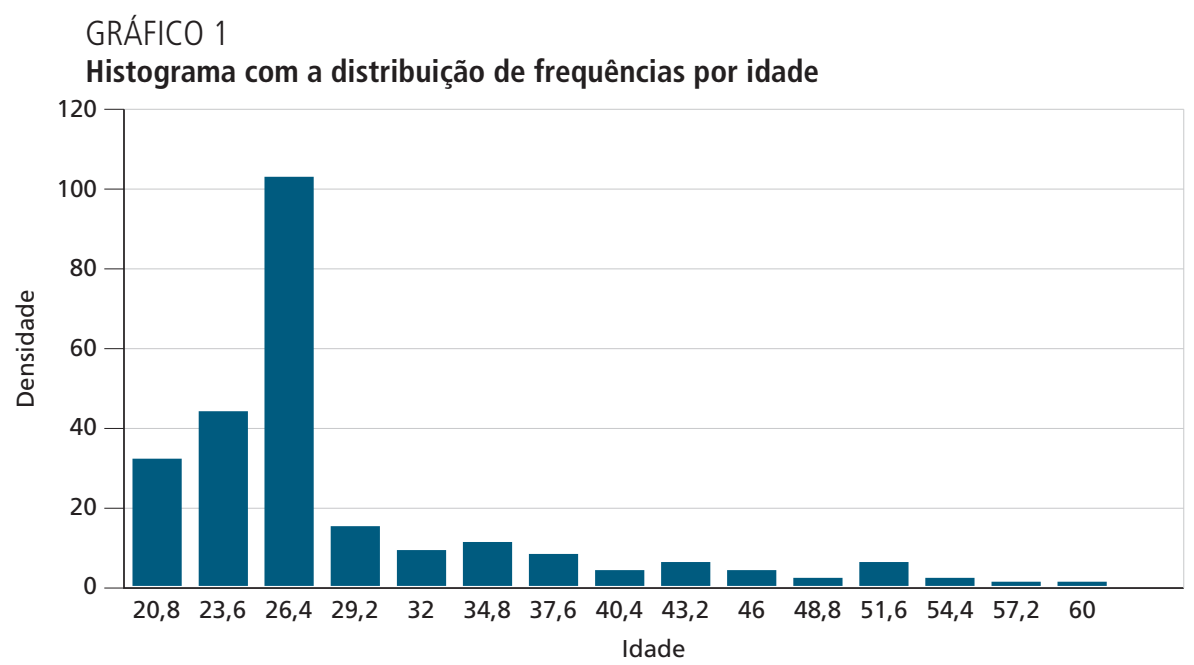

Fonte: Dados da pesquisa.

Elaboração dos autores. 
Através do questionário do Enem, foi possível extrair a informação referente à renda da família do estudante da Furg anterior ao ingresso na instituiçẫo, a qual se pode verificar na tabela 2 , que se encontra organizada sob intervalos de salários mínimos referente ao ano de $2012(\mathrm{R} \$ 622,00)$.

TABELA 2

Distribuição da amostra por intervalos de renda familiar

\begin{tabular}{lcc}
\hline Níveis & Número de familias & $\%$ \\
\hline Até 1,5 SM & 462 & 24,19 \\
Até 3 SMs & 848 & 44,40 \\
Até 6 SMs & 367 & 19,21 \\
Até 8 SMs & 96 & 5,03 \\
Até 10 SMs & 55 & 2,88 \\
Até 15 SMs & 59 & 3,09 \\
Acima de 15 SMs & 23 & 1,20 \\
Total & 1.910 & 100 \\
\hline
\end{tabular}

Fonte: Dados da pesquisa.

Elaboração dos autores.

Percebe-se que um número considerável de famílias (quase 25\%) contava com até um SM e meio para garantir o sustento dos seus membros, ou seja, menos de R \$ 950,00 por mês. Embora não seja possível obter o valor per capita dessa renda familiar, esse é um valor suficientemente baixo e que pode criar um obstáculo para permanência do estudante dentro da universidade, uma vez que, como exposto na revisão da literatura, os aspectos socioeconômicos são fatores decisivos na decisão de evadir, sobretudo porque a permanência nas carteiras de sala de aula representa um custo de oportunidade para aquele aluno que poderia estar trabalhando em alguma atividade remunerada, o que se mostra mais sensível para aqueles alunos em situação mais vulnerável. A tabela 2 ainda mostra que quase metade da amostra é composta por alunos com famílias que auferem rendimentos inferiores a três SMs $(68,59 \%)$.

Outra informação disponibilizada pelo questionário socioeconômico do Enem e apontada pela literatura nacional e internacional como tendo um papel preponderante na vida escolar de um indivíduo é a escolaridade dos pais. A tabela 3 traz esses dados organizados em função dos níveis de educação atingidos pela mãe e pelo pai, respectivamente.

A tabela 3 mostra que, de forma geral, as mães possuem maior nível de escolaridade comparativamente aos pais. Analisando mais de perto, cerca de 32,5\% das mães possuem até o ensino fundamental, esse valor ultrapassa $38 \%$ do total dos pais. Nos demais níveis, o percentual permanece semelhante para ambos os casos, mostrando que cerca de um quarto da amostra possui ensino médio completo e $15 \%$, ensino superior. No entanto, quando se trata de pós-graduação, o número de mães com titulação é duas vezes maior que o número de pais. 
TABELA 3

Escolaridade dos pais por níveis de ensino

\begin{tabular}{|c|c|c|c|c|}
\hline & \multicolumn{2}{|c|}{ Mãe } & \multicolumn{2}{|c|}{ Pai } \\
\hline & Número & $\%$ & Número & $\%$ \\
\hline Não estudou & 49 & 2,57 & 47 & 2,46 \\
\hline Da 1a a 3a série & 261 & 13,66 & 367 & 19,21 \\
\hline Da 5a a 8aㅗie série & 313 & 16,39 & 314 & 16,44 \\
\hline Ensino médio incompleto & 138 & 7,23 & 135 & 7,07 \\
\hline Ensino médio & 508 & 26,6 & 442 & 23,14 \\
\hline Ensino superior incompleto & 121 & 6,34 & 133 & 6,96 \\
\hline Ensino superior & 303 & 15,86 & 271 & 14,19 \\
\hline Pós-graduação & 197 & 10,31 & 99 & 5,18 \\
\hline Não informado & 20 & 1,05 & 102 & 5,34 \\
\hline
\end{tabular}

Fonte: Dados da pesquisa.

Elaboração dos autores.

Obs.: 0 termo série para designar os períodos cursados no ensino básico brasileiro não recebe mais esta nomenclatura. Atualmente, o termo utilizado é ano.

Ademais, a literatura mostra que o desempenho acadêmico presente está correlacionado com o desempenho escolar passado do estudante, corroborando com contribuições semelhantes à de Saccaro, França e Jacinto (2016), que atribuem ao componente esforço um papel central ao longo da trajetória acadêmica do estudante. A tabela 4 traz informaçóes sobre o desempenho prévio ao ingresso na universidade dos alunos que compóem a amostra. As colunas regular referem-se aos estudantes, de seus respectivos níveis, que concluíram a etapa no tempo-padrão - oito anos para o ensino fundamental; três anos para o ensino médio. As colunas interrupção referem-se àqueles alunos que evadiram por um determinado período de tempo, porém, retomaram os estudos e concluíram.

\section{TABELA 4}

Desempenho prévio dos estudantes da Furg

(Em números absolutos)

\begin{tabular}{lccccc}
\hline & \multicolumn{2}{c}{ Ensino fundamental } & & \multicolumn{2}{c}{ Ensino médio } \\
\cline { 2 - 3 } \cline { 5 - 6 } & Regular & Interrupção & & Regular & Interrupção \\
\hline Não & 447 & 1.844 & 726 & 1.729 \\
Sim & 1.463 & 66 & 1.184 & 181 \\
\hline
\end{tabular}

Fonte: Dados da pesquisa.

Elaboração dos autores.

Os dados revelam que o número de reprovaçóes se deu com maior grau no ensino médio. No entanto, quando se observa a variável interrupção, nota-se que essa situação se repetiu mais vezes sobre os alunos do ensino médio. A intuição por 
detrás disto recai, novamente, sobre o conceito de custo de oportunidade: a partir da adolescência, o número de evasão escolar costuma ser reforçado pela necessidade em alocar o tempo em trabalho em detrimento da escola.

Ainda analisando a relação entre desempenho prévio e desempenho atual, o gráfico 2 relaciona o desempenho do estudante na universidade, representado pelo coeficiente de rendimento, o qual se caracteriza como a variável resposta principal deste trabalho, com o desempenho através da nota final do discente no Enem.

Mais uma vez, os dados exprimem a ideia geral de que o desempenho anterior à vida universitária do aluno está condicionado ao seu desempenho prévio. Basta observar que aqueles alunos que obtiveram médias mais baixas no Enem (intervalos de notas no eixo da abcissa do gráfico 2) reproduzem um resultado semelhante dentro da universidade, ao passo que os alunos que obtiveram notas altas permaneceram atingindo um desempenho mais alto, expresso pelo coeficiente de rendimento, uma medida de desempenho dos estudantes que é calculada pelo somatório do total das notas obtidas em cada disciplina cursada, ponderado pelos respectivos créditos.

\section{GRÁFICO 2}

Correlação entre desempenho universitário e desempenho na prova do Enem

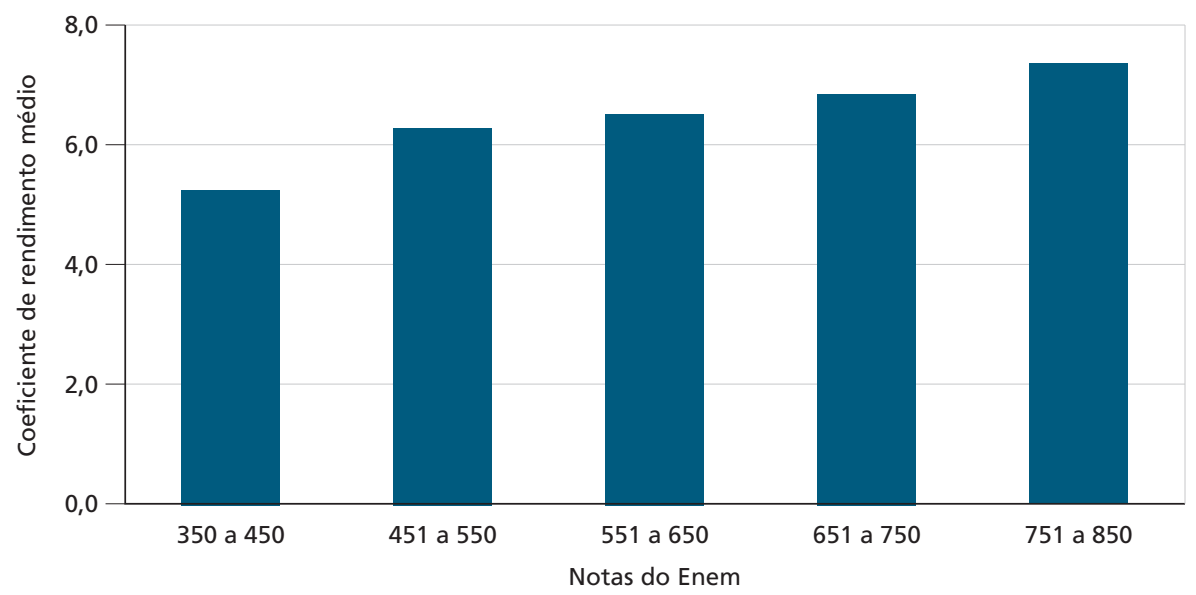

Fonte: Dados da pesquisa.

Elaboração dos autores.

Uma vez que o baixo desempenho acadêmico costuma influenciar diretamente na decisão de evadir, corrigir este resultado passou a integrar atuação e condução de políticas de permanência dos alunos, sobretudo aqueles que se encontrem na margem de uma referência de ideal. Nessa perspectiva se encaixam os objetivos traçados pelo PNAES, que visam contribuir para a redução da evasão e da retenção entre os discentes socioeconomicamente identificados como vulneráveis e, assim, 
qualificar o desempenho acadêmico dos estudantes dos cursos de graduação das Ifes. As ações de assistência estudantil do PNAES buscam contemplar dez áreas. Algumas açôes são destinadas exclusivamente a estudantes que participam do $\mathrm{SAB}$, tais como moradia estudantil, alimentação, transporte e creche. A tabela 5 apresenta a relação de alunos beneficiários de alguns desses auxílios assistenciais.

TABELA 5

Relação de alunos que recebem algum tipo de assistência pela universidade

\begin{tabular}{lcccccc}
\hline & Alimentação & Moradia & Monitoria & Transporte & Bolsa & Creche \\
\hline Sim & 376 & 72 & 79 & 330 & 215 & 23 \\
$\%$ & 19,69 & 3,77 & 4,14 & 17,28 & 11,26 & 1,20 \\
Não & 1.534 & 1.838 & 1.831 & 1.580 & 1.695 & 1.887 \\
$\%$ & 80,31 & 96,23 & 95,86 & 82,72 & 88,74 & 98,80 \\
\hline
\end{tabular}

Fonte: Dados da pesquisa.

Elaboração dos autores.

Em suma, a tabela 5 elenca os principais benefícios concedidos a estudantes identificados em situação de vulnerabilidade socioeconômica. Quase 20\% da amostra recebe auxílio-alimentação, o que lhe confere o direito de fazer as refeiçóes diárias no restaurante universitário; $17 \%$ recebem auxílio-transporte em forma de créditos para utilizar o transporte urbano municipal; $11 \%$ recebem bolsa permanência, um auxílio financeiro no valor de $\mathrm{R} \$ 400,00$, em 2015; em menor número, aparecem: o auxílio-moradia, que garante o direito ao estudante de morar na Casa do Estudante Universitário; o auxílio-monitoria, que garante uma bolsa no valor de $\mathrm{R} \$ 400,00$, em 2015 , para o estudante devidamente selecionado para desempenhar a função de monitor de determinada disciplina; e, por fim, o auxílio-creche, que concede aos estudantes com filhos entre 0 e 6 anos de idade o pagamento da creche durante os períodos em que estiver em sala de aula.

Além desses benefícios, há uma parcela de alunos que é contemplada com mais de um benefício. No entanto, para os fins deste trabalho, a implementação do método busca avaliar o impacto do recebimento de quatro dos seis auxílios apresentados na tabela 5 que contém um número de observaçóes que permitam inferir sobre os resultados esperados - a citar, auxílio-alimentação, auxílio-moradia, auxílio-transporte e bolsa permanência - sobre o desempenho acadêmico, medido pela média do coeficiente do rendimento. Para tanto, utilizar-se-á de um conjunto de variáveis observáveis, tais como as que foram apresentadas nessa breve descrição de dados, para formar um grupo de comparação o mais próximo possível do grupo de alunos beneficiários, para que então se consiga medir o efeito médio de tratamento sobre os tratados, isto é, a diferença média dos resultados obtidos pelo grupo de tratados e pelo seu contrafactual, o grupo controle estipulado com base no escore de propensão. 


\section{RESULTADOS}

A proposta deste estudo consiste na comparação do desempenho médio obtido por alunos que foram beneficiários de um conjunto de auxílios proporcionados pela Furg através do PNAES versus os alunos não beneficiários, a fim de medir o efeito do programa. À primeira vista, uma simples diferença de médias de resultados entre os dois grupos parece sanar este questionamento. A tabela 6 cumpre este propósito ao trazer um teste de diferenças de médias entre os dois grupos.

TABELA 6

Distribuição das frequências e testes de diferenças de médias das amostras

\begin{tabular}{|c|c|c|c|c|c|c|c|c|}
\hline \multirow{2}{*}{ Benefício } & \multicolumn{2}{|c|}{ Bolsa permanência } & \multicolumn{2}{|c|}{ Alimentação } & \multicolumn{2}{|c|}{ Moradia } & \multicolumn{2}{|c|}{ Transporte } \\
\hline & Número & Média & Número & Média & Número & Média & Número & Média \\
\hline Controle & 1.695 & 6,68 & 1.534 & 6,64 & 1.838 & 6,69 & 1.580 & 6,64 \\
\hline Tratamento & 215 & 6,93 & 376 & 6,99 & 72 & 7,23 & 330 & 7,07 \\
\hline Diferença & - & $0,24^{*}$ & - & $0,35^{* * *}$ & - & $0,54^{* *}$ & - & $0,43^{* * *}$ \\
\hline
\end{tabular}

Fonte: Dados da pesquisa.

Elaboração dos autores.

Obs.: ${ }^{* * *}$ significativo a $1 \% ;{ }^{* *}$ significativo a $5 \%$; ${ }^{*}$ significativo a $10 \%$.

$\mathrm{Na}$ tabela 6, o grupo chamado de controle envolve os discentes que não receberam o benefício e o grupo denominado de tratamento foi o que recebeu o benefício. Conforme se observa, o teste mostrou haver uma diferença estatisticamente significativa entre os grupos, de modo que aqueles que receberam algum benefício possuem um coeficiente de rendimento superior ao restante da amostra, composta por alunos não beneficiários. Todavia, não se deve cometer $o$ erro de atribuir a esta diferença o efeito do recebimento do auxílio em questáo. Esta diferença pode estar associada a uma série de fatores que não estão sendo considerados nessa simples análise.

O primeiro passo para realizar a estimação do impacto do programa consiste em formar um grupo de comparação o mais semelhante possível ao grupo de beneficiários, isto é, um contrafactual. Para tanto, é feito o pareamento pelo escore de propensão das observaçóes através da probabilidade de participar do programa. Para isso, utilizou-se o método Probit, com o auxílio do software estatístico e de análise de dados, Stata. As tabelas 7, 8 e 9 apresentam o resultado do pareamento pelo escore de propensão para os quatro benefícios.

As variáveis que compóem o modelo são apresentadas na tabela 7 , de modo que as especificaçôes dos modelos, embora tenham algumas variáveis em comum, diferem entre si, em vista de estimar resultados os mais robustos possíveis. A variável idade representa a idade contínua dos estudantes, presente em todos os modelos, apresentando significância de, no mínimo, 10\%. O sinal negativo indica que, à 
medida que a idade aumenta, diminui a probabilidade de se tornar beneficiário de todos os benefícios. As variáveis referentes às faixas de renda familiar são variáveis dummies, que indicam em que sentido se altera a probabilidade do estudante, cuja família aufere renda neste intervalo, em ser beneficiário do programa comparativamente à faixa de renda, a qual serve de referência para as demais categorias. Quantitativamente, na primeira faixa encontram-se famílias com rendas de até 3 SMs, a seguir, famílias com renda entre 3 e 7 SMs, famílias com renda entre 7 e 12 SMs e, por fim, com rendas superiores a 12 SMs.

\section{TABELA 7 \\ Escores de propensão das estimações Probit}

\begin{tabular}{|c|c|c|c|c|}
\hline Variável & Bolsa permanência & Alimentação & Moradia & Transporte \\
\hline \multirow{2}{*}{ Idade } & $-0,0239 * * *$ & $-0,0218^{* * *}$ & $-0,0268^{* * *}$ & $-0,0094^{* *}$ \\
\hline & $(0,0064)$ & $(0,0051)$ & $(0,0103)$ & $(0,0047)$ \\
\hline \multirow{2}{*}{ Faixa de renda 2} & $-0,4524^{* * *}$ & $-0,6517^{* * *}$ & $-0,4759^{* * *}$ & $-0,6230^{* * *}$ \\
\hline & $(0,1155)$ & $(0,1032)$ & $(0,1565)$ & $(0,1079)$ \\
\hline \multirow{2}{*}{ Faixa de renda 3} & Omitido & $-1,2786 * * *$ & Omitido & $-1,4111^{* * *}$ \\
\hline & - & $(0,3097)$ & - & $(0,3916)$ \\
\hline \multirow{2}{*}{ Faixa de renda 4} & Omitido & $-0,8941 * * *$ & $-0,6060$ & $-0,9838^{* * *}$ \\
\hline & - & $(0,3338)$ & $(0,4208)$ & $(0,4221)$ \\
\hline \multirow{2}{*}{ Curso matutino } & $-0,0301$ & $-0,2213$ & $-0,6430^{* * *}$ & 0,0805 \\
\hline & $(0,2146)$ & $(0,1953)$ & $(0,2373)$ & $(0,2041)$ \\
\hline \multirow{2}{*}{ Curso vespertino } & 0,1069 & $-0,4281^{* *}$ & $-0,9597^{* * *}$ & 0,3122 \\
\hline & $(0,2330)$ & $(0,2149)$ & $(0,3087)$ & $(0,2193)$ \\
\hline \multirow{2}{*}{ Curso noturno } & $-0,4917^{* *}$ & $-0,8546^{* * *}$ & $-0,8989 * * *$ & $-0,4066^{* *}$ \\
\hline & $(0,2196)$ & $(0,1980)$ & $(0,2467)$ & $(0,2060)$ \\
\hline \multirow{2}{*}{ Fundamental público } & $0,3859 * * *$ & $0,4079^{* * *}$ & - & $0,3182^{* * *}$ \\
\hline & $(0,0991)$ & $(0,0853)$ & - & $(0,0966)$ \\
\hline \multirow{2}{*}{ Média Enem } & $-0,0018^{* * *}$ & $-0,0012^{* *}$ & - & - \\
\hline & $(0,0005)$ & $(0,0005)$ & - & - \\
\hline \multirow{2}{*}{ Interrompeu fundamental } & $0,3818^{*}$ & - & - & - \\
\hline & $(0,2163)$ & - & - & - \\
\hline \multirow{2}{*}{ Fundamental regular } & $-0,2546^{* *}$ & - & - & - \\
\hline & $(0,0988)$ & - & - & - \\
\hline \multirow{2}{*}{ Acesso à internet } & - & $-0,2967^{* * *}$ & - & - \\
\hline & - & $(0,0933)$ & - & - \\
\hline
\end{tabular}




\begin{tabular}{|c|c|c|c|c|}
\hline Variável & Bolsa permanência & Alimentação & Moradia & Transporte \\
\hline \multirow{2}{*}{ Preto } & - & 0,2064 & - & - \\
\hline & - & & $(0,1397)$ & - \\
\hline \multirow{2}{*}{ Pardo } & - & $0,2494^{* *}$ & - & - \\
\hline & - & & $(0,1035)$ & - \\
\hline \multirow{2}{*}{ Amarelo } & - & Omitido & - & - \\
\hline & - & - & - & - \\
\hline \multirow{2}{*}{ Indígena } & - & Omitido & - & - \\
\hline & - & - & - & - \\
\hline \multirow{2}{*}{ Homem } & - & - & 0,1605 & $-0,2864^{* * *}$ \\
\hline & - & - & $(0,1138)$ & $(0,0783)$ \\
\hline \multirow{2}{*}{ Oriundo de escola pública } & - & - & - & 0,0082 \\
\hline & - & - & - & $(0,1099)$ \\
\hline \multirow{2}{*}{ Constante } & $0,7812^{*}$ & $1,1984^{* * *}$ & $-0,3305$ & $1,3901 * * *$ \\
\hline & $(0,4614)$ & $(0,4237)$ & $(0,3631)$ & $(0,4287)$ \\
\hline
\end{tabular}

Fonte: Dados da pesquisa.

Elaboração dos autores.

Obs.: $1 .{ }^{* *}$ significativo a $1 \% ;{ }^{* *}$ significativo a $5 \%$; ${ }^{*}$ significativo a $10 \%$.

2. Onde está escrito omitido, a omissão se deveu a problemas de colinearidade.

O que se observa é que, com exceção dos casos em que houve omissão em função de colinearidade e de um único coeficiente que não obteve significância estatística, todos os demais se mostraram significativos ao nível de $1 \%$, indicando que à medida que aumenta a renda familiar diminui as chances, por assim dizer, de o aluno compor o grupo de controle da amostra.

Análise semelhante ocorre com as dummies referentes ao turno em que o estudante cursa a faculdade. Neste caso, a comparação é feita com referência à variável integral, ou seja, comparativamente aos alunos que estudam em tempo integral (manhã e tarde), de que forma as outras categorias influenciam as chances de o estudante integrar o grupo de controle? Nos casos em que os coeficientes apresentaram valores significativos, esses indicaram uma relação inversa, ou seja, diminui a probabilidade.

Algumas indicaçóes interessantes da tabela 7, relativas aos resultados do pareamento da amostra, é o sentido em que a probabilidade atua em certos casos leva a crer que o grupo de controle, de fato, deve ser composto por aqueles estudantes identificados como sendo mais vulneráveis.

Além de aumentar a probabilidade quanto menor for a renda, como já mencionado, aqueles que obtiveram médias mais baixas no Enem (bolsa permanência e alimentação) também têm mais chances de integrar o contrafactual, como aqueles 
que estudaram em escola pública no ensino fundamental, interromperam o ensino fundamental em algum momento ou não terminaram o fundamental em tempo regular (casos para bolsa permanência), além do que, aqueles que possuíam acesso à internet em suas casas apresentaram menores chances de integrar o grupo de controle para o recebimento de auxílio-alimentação.

É importante ressaltar que o pareamento de duas amostras pode ser feito com base em diferentes métodos. O método mais comum é o pareamento com o vizinho mais próximo, em que todas as unidades tratadas encontram um par o mais semelhante possível. No entanto, alguns desses pareamentos são pobres devido ao fato de que para algumas unidades tratadas o vizinho mais próximo possa ter um escore de propensão bem diferente. Portanto, métodos como o Radial e o Kernel, entre outros, oferecem uma solução para este problema. O primeiro impóe uma distância máxima tolerável entre os escores de propensão, de modo que, quanto menor essa tolerância melhor o pareamento, porém, maiores as chances de que algumas unidades tratadas não encontrem pares. O segundo, o Kernel, consiste em um estimador de pareamento não paramétrico que utiliza médias ponderadas de todos os indivíduos no grupo de controle para construir um contrafactual. A sua maior vantagem se baseia em uma variância menor devido ao menor número de informaçôes utilizadas. No entanto, por outro lado, corre o risco de utilizar-se de controles ruins.

\section{TABELA 8}

\section{Balanceamento do pareamento das amostras para os recebimentos de bolsas}

\begin{tabular}{llrrrrr}
\hline & & Pseudo $\mathrm{R}^{2}$ & $\mathrm{LR} \chi^{2}$ & Prob $>\chi^{2}$ & Viés & $\mathrm{R}$ \\
\hline \multirow{2}{*}{ Bolsa permanência } & Não pareada & 0,09 & 116,67 & 0 & 82,4 & 0,69 \\
& Pareada & 0 & 0,13 & 1 & 3,5 & 1,03 \\
\hline \multirow{2}{*}{ Alimentação } & Não pareada & 0,137 & 258,54 & 0 & 98,3 & 0,54 \\
& Pareada & 0 & 0,32 & 1 & 5,2 & 1 \\
\multirow{2}{*}{ Moradia } & Não pareada & 0,059 & 35,93 & 0 & 75,3 & 0,66 \\
& Pareada & 0 & 0,07 & 1 & 4,3 & 0,8 \\
\multirow{2}{*}{ Transporte } & Não pareada & 0,143 & 251,93 & 0 & 101,7 & 0,51 \\
& Pareada & 0 & 0,31 & 1 & 4,3 & 1,02 \\
\hline
\end{tabular}

Fonte: Dados da pesquisa.

Elaboração dos autores.

Diversos métodos e especificaçóes foram testados neste trabalho a fim de obter os melhores resultados - a citar: o método Radial, com distância máxima entre as observaçóes de 0,01 e 0,05; o Kernel, de 0,01; o método de vizinhança mais próxima, com cinco observações de controle para uma tratada; e, por fim, o método de vizinhança mais próxima sem reposição. A verificação da qualidade do pareamento se dá através do balanceamento conforme exibe a tabela $8 .{ }^{19}$ 
O balanceamento serve para dar sustento à condição de que após o pareamento não restem diferenças nas características dos indivíduos tratados e não tratados. Ocorre um bom ajuste após a amostra ter sido pareada, tendo significantes quedas no Pseudo- $\mathrm{R}^{2}$. A proporção das variâncias do índice de escore de propensão dos tratados para os não tratados (pareados), representado por $R$, devem estar entre um intervalo entre 0,5 e 2 (Rosenbaum e Rubin, 1985). Ademais, uma das principais estatísticas de interesse para o correto balanceamento é o viés após o pareamento, o qual é desejável que obtenha um valor abaixo de 5\%, de acordo com Grilli e Rampichini (2011). Com exceção do benefício alimentação, todos os demais obtiveram uma redução significativa, permanecendo com um nível de viés abaixo de 5\%.

A tabela 9 traz a principal contribuição deste estudo. Após realizar o pareamento das amostras e testar a qualidade dele, cabe agora mostrar o resultado do impacto do recebimento dos benefícios sobre o desempenho dos alunos. Para tanto, basta fazer a diferença das médias obtidas em ambos os grupos, os tratados e o controle. Neste caso, qual foi o impacto no desempenho daqueles alunos que não foram contemplados com o auxílio assistencial, mas que possuem características que os tornam elegíveis - a tentativa de reproduzir qual teria sido o resultado dos beneficiários, caso não tivessem sido expostos ao tratamento, é o que chamamos de efeito médio sobre os tratados (ou average treatment effect on treated - ATT).

TABELA 9

Efeitos de tratamento do recebimento dos benefícios

\begin{tabular}{llrrrr}
\hline & & Bolsa & Alimentação & Moradia & Transporte \\
\hline \multirow{2}{*}{ Radial $(0,01)$} & ATT & 0,3370 & 0,5216 & 0,6944 & 0,5180 \\
& Erro-padrão & $(0,1658)$ & $(0,1410)$ & $(0,2383)$ & $(0,1487)$ \\
\hline \multirow{2}{*}{ Radial $(0,03)$} & ATT & 0,3528 & 0,5342 & 0,6286 & 0,5433 \\
& Erro-padrão & $(0,1630)$ & $(0,1379)$ & $(0,2336)$ & $(0,1451)$ \\
\hline \multirow{2}{*}{ Kernel $(0,01)$} & ATT & 0,3556 & 0,5201 & 0,7022 & 0,5556 \\
& Erro-padrão & $(0,1666)$ & $(0,1413)$ & $(0,2386)$ & $(0,1493)$ \\
\hline \multirow{2}{*}{ 5-NN } & ATT & 0,3884 & 0,4861 & 0,5353 & 0,5682 \\
& Erro-padrão & $(0,1830)$ & $(0,1503)$ & $(0,2917)$ & $(0,1613)$ \\
\hline \multirow{2}{*}{ 1-NN SR } & ATT & 0,2879 & 0,4047 & 0,8361 & 0,6703 \\
& Erro-padrão & $(0,1458)$ & $(0,1130)$ & & $(0,1159)$ \\
\hline
\end{tabular}

Fonte: Dados da pesquisa.

Elaboração dos autores.

Obs.: NN-5 (5-Nearest neighbors): utiliza as cinco observações mais próximas para realizar o pareamento; 1-NN SR (1-Nearest Neighbor - One-to-one): utiliza o vizinho mais próximo para realizar o pareamento, sem considerar reposiç̧ão das observações.

Com exceção dos resultados obtidos para o recebimento de auxílio moradia pelo método de pareamento de vizinhança mais próxima, com cinco unidades de controle para uma unidade tratada, e para o recebimento de auxílio transporte, com o método de pareamento de vizinhança mais próxima sem reposição, todos 
os demais coeficientes obtidos apresentaram significância estatística, o que permite inferir que a concessão de bolsas causa um efeito positivo sobre o desempenho dos alunos. No caso da bolsa permanência, o impacto varia entre 0,28 e 0,38 pontos; para o recebimento de alimentação, o resultado apontou um aumento médio entre 0,40 e 0,53 pontos; moradia obteve valores mais altos, entre 0,62 e 0,83 e, por fim; o auxílio transporte, com um efeito médio entre 0,51 e 0,67. Em suma, os resultados obtidos pelo método são superiores, inclusive àqueles obtidos por uma simples diferença de médias (tabela 6).

Dessa forma, portanto, evidencia-se a eficácia das políticas voltadas para a permanência e o desempenho dos estudantes na Furg. A hipótese utilizada aqui é a de que, se o desempenho dos discentes que receberam o benefício (grupo tratado) for superior ou igual ao desempenho dos que não receberam (grupo controle), entấo o benefício como política pública que visa contribuir para a diminuição da evasão, principalmente, está atingindo seu objetivo.

A limitação, em termos de método e dados, contudo, refere-se à validade externa dos resultados, ou seja, a impossibilidade de estender e generalizar tais resultados para outras instituiçóes, embora este tipo de trabalho possa representar passos quase que pioneiros no sentido de conduzir avaliaçôes junto às universidades de maneira sistematizada, a fim de observar se essas estratégias estão obtendo os resultados desejados e apresentar propostas para implementação e melhorias. Lembrando que o relatório de CGU (2017) indicou que, até o presente momento, não há uniformidade entres as Ifes no processo de concessão dos benefícios. Portanto, trabalhos futuros que envolvam várias instituiçôes públicas de ensino superior devem controlar o fato de não haver uniformidade na forma como os benefícios do PNAES são geridos entre as universidades públicas. Este contexto também sugere que instrumentos de avaliação de políticas públicas, tais como o que foi utilizado neste artigo, sejam aplicados sempre em cada IES, e não de forma agregada, dada a heterogeneidade verificada por CGU (2017).

\section{CONSIDERAÇÕES FINAIS}

A revisão da literatura realizada neste artigo, em conjunto com os resultados obtidos, mostrou a importância de se possuir uma base de dados que tenha tanto as informaçóes do desempenho dos estudantes no ensino superior quanto suas características pregressas ao ingresso na universidade, a fim de se verificar o efeito dos benefícios concedidos pelo programa PNAES. Existe uma riqueza de informaçôes, anteriores ao ingresso dos estudantes no ensino superior, disponíveis na base de dados daqueles que responderam ao questionário socioeconômico do Enem. Várias dessas informaçóes serviram de subsídio para as estimaçóes realizadas neste trabalho com o objetivo de mostrar o efeito dos benefícios concedidos pelo PNAES via PSM. 
Após parear as amostras, e verificar a qualidade deste pareamento, obteve-se como resultado um impacto positivo do recebimento dos benefícios - alimentação, moradia, transporte e bolsa permanência - sobre o desempenho dos alunos. Utilizando o coeficiente de rendimento como parâmetro de desempenho, ficou evidenciado que estudantes beneficiados com auxílio moradia ficaram entre 0,62 e 0,83 acima do grupo de controle; os beneficiados com transporte, entre 0,51 e 0,67 acima; os beneficiados com alimentação, entre 0,40 e 0,53 acima; e, por fim, os beneficiados com bolsa permanência ficaram entre 0,28 e 0,38 acima.

O questionário socioeconômico do Enem, utilizado como parte da base de dados neste artigo, foi disponibilizado para as instituiçóes de ensino no passado recente, e fornece as respostas dos discentes que ingressaram na universidade. Mas isto não é mais feito. $\mathrm{O}$ retorno de tal prática contribuiria para qualificar o conjunto de informação que vier a ser utilizado nas diversas ferramentas de análise, como a efeitos dos benefícios concedidos pelo PNAES. Inclusive, a conciliação dos dados do questionário socioeconômico do Enem que foi utilizado neste artigo envolveu apenas os anos de 2011 e 2012, mas a pesquisa poderia ter sido mais abrangente na base de dados caso a disponibilização dos dados de 2013 em diante tivesse sido mantida.

Este artigo espera ter colaborado para a discussão sobre o efeito de políticas sociais para combater a evasão e a retenção dos estudantes do ensino superior para o caso brasileiro. Foi possível medir que o grupo que recebeu o benefício respondeu positivamente ao tratamento. Ressalta-se, porém, que não é possível extrapolar os resultados obtidos nesse estudo para diferentes amostras e diferentes períodos. Entende-se que o uso da econometria pode ser um forte aliado ao aprimoramento deste tipo de programa, visando à permanência e ao melhor desempenho dos alunos no ensino superior.

\section{REFERÊNCIAS}

BORGES, S. M. Fatores determinantes da evasão escolar no ensino superior: o estudo de caso do Iles/Ulbra de Itumbiara. 2011. Dissertaçấo (Mestrado) - Faculdades Alves Faria, Goiânia, 2011.

BRATTI, M. Parents' income and children's school drop-out at 16 in England and Wales: Evidence from the 1970 British Cohort Study. Rev Econ Household, Milan, p.15-40, 2007.

CAPPELLI, P.; WON, S. How you pay affects how you do: financial aid type and student performance in college. Cambridge: NBER, 2016. (Working Paper, n. 22604). Disponível em: <https://bit.ly/31DmSMu>. Acesso em: 30 jun. 2017. 
CGU - CONTROLADORIA-GERAL DA UNIÃO. Relatório Consolidado PNAES. Brasília: CGU, 2017.

CISLAGHI, R. Um modelo de sistema de gestáo do conhecimento em um framework para a promoçáo da permanência discente no ensino de graduaçáo. 2008. Tese (doutorado) - Universidade Federal de Santa Caratina, Santa Catarina, 2008. Disponível em: <https://bit.ly/3lndvIL>

COSTA, A.; LOPES, J. Os estudantes e os seus trajectos no ensino superior: sucesso e insucesso, factores e processos, promoção de boas práticas. [s.l.]: Cies, 2008.

DUENHAS, R.; FRANÇA, M.; GONÇALVES, F. Abrir as escolas à comunidade nos finais de semana reduz que tipo de violência? Uma análise de contrafactual utilizando mínimos quadrados ponderados pelo propensity score. Planejamento e Políticas Públicas, n. 37, jul./dez. 2011.

FRANÇA, M. GONÇALVES, F. Provisão pública e privada de educação fundamental: diferenças de qualidade medidas por meio de propensity score matching. Economia Aplicada, Ribeirão Preto, v. 14, n. 4, 2010.

FURG - UNIVERSIDADE FEDERAL DO RIO GRANDE. Instrução Normativa no 3/2011, sobre normas para a inclusão e permanência de Alimentação Estudantil. Rio Grande: Furg, 2011a. Disponível em: <https://bit.ly/2Thso2R>. Acesso em: 6 set. 2018.

Instruçáo Normativa no 4/2011, sobre normas para a inclusão e a permanência transporte estudantil. Rio Grande: Furg, 2011b. Disponível em: <https:// bit.ly/2Thso2R>. Acesso em: 6 set. 2018.

Instruçáo Normativa no $\mathbf{2}$ /2011, sobre normas para a inclusão e permanência de moradia estudantil. Rio Grande: Furg, 2011c. Disponível em: <https:// bit.ly/2Thso2R>. Acesso em: 6 set. 2018.

Instruçáo Normativa no $\mathbf{1 / 2 0 1 6}$, sobre acompanhamento pedagógico ao estudante. Rio Grande: Furg, 2016. Disponível em: <https://bit.ly/2Thso2R>. Acesso em: 6 set. 2018.

GILIOLI, R. S. P. Evasão em instituiçóes federais de ensino superior no Brasil: expansão da rede, Sisu e desafios. Brasília: Câmara dos Deputados, maio 2016. (Estudo Técnico).

GRILLI, L.; RAMPICHINI, C. Propensity scores for the estimation of ATE in observational studies. In: TRANING SESSIONS ON CAUSAL INFERENCE, 2011, Bristol. Notas... Bristol: [s.n.], jun. 2011. Disponível em: <https://bit. ly/2Ilf6R $4>$. 
INEP - INSTITUTO NACIONAL DE ESTUDOS E PESQUISAS EDUCACIONAIS ANÍSIO TEIXEIRA. Censo da Educaçáo Superior 2014: resumo técnico. Brasília: Inep, 2016.

LI, D. L. O novo Enem e a plataforma Sisu: efeitos sobre a migração e a evasão estudantil. 2016. Dissertação (Mestrado) - Universidade de São Paulo, São Paulo, 2016. Disponível em: <https://bit.ly/2TnnDVr>. Acesso em: 6 set. 2018.

LIBÂNEO, J. C. Didática. São Paulo: Editora Cortez, 2007.

LIMA JÚNIOR, P.; OSTERMANN, F.; REZENDE, F. Análise dos condicionantes sociais da evasão e retenção em cursos de graduação em física à luz da sociologia de Bourdieu. Revista Brasileira de Pesquisa em Educaçáo em Ciências, v. 12, n. 1, p. 37-60, 2012.

MACHADO, C.; SZERMAN, C. The effects of a centralized college admission mechanism on migration and college enrollment: evidence from Brazil. [s.l.]: Lacea, 2015. (Working Paper Lacea).

MAHUTEAU, S.; MAVROMARAS, K. An analysis of the impact of socioeconomic disadvantage and school quality on the probability of school dropout. Bonn: Institute of Labor Economics (IZA), Ago. 2013. (Discussion Paper n. 7566).

MARTINS, C. B. N. Evasáo de alunos nos cursos de graduaçáo em uma instituição de ensino superior. 2007. Dissertação (Mestrado) - Fundação Pedro Leopoldo, Minas Gerais, 2007. Disponível em: <https://bit.ly/2Iqnw9y>. Acesso em: 6 set. 2018.

. A reforma universitária de 1968 e a abertura para o ensino superior privado no Brasil. Educaçáo e Sociedade, Campinas, v. 30, n. 106, p. 15-35, jan./abr. 2009. NOGUEIRA, C.; NOGUEIRA, M. A sociologia da educação de Pierre Bourdieu: limites e contribuiçôes. Educaçáo e Sociedade, Campinas, v. 23, n. 78, p. 15-35, abr. 2002.

ROSENBAUM, P.; RUBIN, D. The central role of the propensity score in observational studies for causal. Biometrika, v. 70, n. 1, p. 41-55, abr. 1983.

Constructing a control group using multivariate matched sampling methods that incorporate the propensity score. The American Statistician, v. 39, n. 1, fev. 1985.

RUMBERGER, R.; LIMA, S. A. Why students drop out: a review of 25 years of research. Santa Barbara: University of California, 2008. (California Dropout Research Project). Disponível em: <https://bit.ly/36Gamxv>.

SACCARO, A.; FRANÇA, M.; JACINTO; P. Retenção e evasão no ensino superior brasileiro: uma análise dos efeitos da bolsa permanência do PNAES. 
In: ENCONTRO NACIONAL DE ECONOMIA ANPEC, 44., 2016, Foz do Iguaçu, Paraná. Anais... Foz do Iguaçu: Anpec, 2016.

SANTOS, P. V. S. Adaptaçáo à universidade dos estudantes cotistas e náo cotistas: relação entre vivência acadêmica e intenção de evasão. 2013. Dissertação (Mestrado) - Universidade Federal da Bahia, Salvador, 2013. Disponível em: $<$ https://bit.ly/3mgagCS>. Acesso em: 30 jun. 2017.

SOUSA, J. N. et al. Principais fatores que impactam na reprovação e evasão dos alunos dos cursos tecnológicos no instituto federal de ciência e tecnologia do Ceará. In: ENCONTRO DE ECONOMIA DO CEARÁ - IPECE, 2015, 11., Fortaleza, Ceará. Anais... Fortaleza: Ipece, 2015. Disponível em: <https://bit.ly/3kvXKyE>. Acesso em: 30 jun. 2017.

TINTO, V. Dropout from higher education: a theoretical synthesis of recent research. Review of Educational Research, Washington, v. 45, n. 1, p. 89-125, 1975.

. Leaving college: rethinking the causes and cures of student attrition. 2. ed. Chicago: University of Chicago Press, 1993.

TRINDADE, H. Saber e poder: os dilemas da universidade brasileira. Estudos Avançados, v. 14, n. 40, p. 122-133, 2000.

\section{BIBLIOGRAFIA COMPLEMENTAR}

BRASIL. Ministério da Educação. Plano Nacional de Assistência Estudantil (PNAES). Brasília: MEC, 2016. Disponível em: <https://bit.ly/3jpz5dI>. Acesso em: 5 out. 2016.

CAMPELLO, A. V. C.; LINS, L. N. Metodologia de análise e tratamento da evasão e retenção em cursos de graduação de instituições federais de ensino superior. In: ENCONTRO NACIONAL DE ENGENHARIA DE PRODUÇÃO, 28., 2008, Rio de Janeiro. Anais... Rio de Janeiro: Abepro, 2008. Disponível em: <https:// bit.ly/3ln $44 \mathrm{sH}>$. Acesso em: 15 out. 2016.

FRANCIS, L. P. In defense of affirmative action. In: CAHN, S. M. (Ed.). Affirmative Action and University: a philosophical inquiry. Philadelphia: Tempe University Press, 1993.

GOLDEMBERG, J. O repensar a educação no Brasil. Estudos Avançados, São Paulo, v. 7, n. 18, 1993.

KIPNIS, B. A pesquisa institucional e a educação superior brasileira: um estudo de caso longitudinal da evasão. Linhas Críticas, Brasília, v. 6, n. 11, p. 109-130, jul./dez. 2000. 
MELLO, J. C. R. Desigualdades sociais e acesso seletivo ao ensino superior no Brasil no período 1994-2001. Revista Electrónica Iberoamericana sobre Calidad, Eficacia y Cambio en Educación, Madrid, v. 5, n. 2, p. 69-83, 2007. Disponível em: <https://bit.ly/2HnleI2>. Acesso em: 5 out. 2016.

ROSA, M. Limites da democratizaçáo da educação superior: entraves na permanência e a evasão na Universidade Federal de Goiás. Poíesis Pedagógica, Catalão, v. 12, n. 1, p. 240-257, jan./jun. 2014.

SILVA, G. P. Análise de evasáo no ensino superior: uma proposta de diagnóstico de seus determinantes. Avaliaçáo: revista da avaliaçáo da educaçáo (Campinas), v. 18, n. 2, p. 311-333, 2013. Disponível em: <https://bit.ly/3pCx2XS>.

SILVA FILHO, R. L. et al. A evasão do ensino superior brasileiro. Cadernos de Pesquisa, São Paulo, v. 37, n. 132, p. 641-659, 2007.

VASCONCELOS, N. B. Programa Nacional de Assistência Estudantil: uma análise da evolução da assistência estudantil ao longo da história da educação superior no Brasil. Ensino em Re-vista, v. 17, n. 2, 2010. Disponível em: <https://bit. ly/3dY88fV >. Acesso em: 6 out. 2016.

Data da submissão: 26/3/2018

Primeira decisão editorial em: 13/6/2018

Última versão recebida em: 25/10/2018

Aprovação final em: 12/11/2018 
